\title{
Heating Mechanism of Unprotected Steel Beam Installed Beneath Ceiling and Exposed to a Localized Fire: Verification using the real-scale experiment and effects of the smoke layer
}

\author{
TAKASHI WAKAMATSU* \\ Institute of Construction Technology, Kumagai Gumi Co.,LTD. \\ Onigakubo1043, Tsukuba, Ibaraki 300-2651,Japan \\ YUJI HASEMI \\ Department of Architecture School of Science and Engineering \\ Waseda University \\ Okubo 3-4-1, Shinjuku, Tokyo169-8555, Japan
}

KOJI KAGIYA

National Institute for Land and Infrastructure Management

Tatehara 1,Tsukuba, Ibaraki 305,Japan

DAISUKE KAMIKAWA

Department of Architecture School of Science and Engineering

Waseda University

Okubo 3-4-1, Shinjuku, Tokyo 169-8555, Japan

\begin{abstract}
Measurements of the heating condition of a steel beam installed beneath a ceiling and exposed to a localized fire source are made on a real-scale experiment. The data of thermal response obtained from the experiments are compared with previous small-scale experiments. The effects of the smoke layer which influences upon the heating condition of the beam are investigated through the smoke experiments setting the smoke protection soffits to the same experimental equipment. FDM-based calculation is demonstrated using the average temperature of the smoke layer for the boundary conditions to predict the thermal response of the beam. Applicability of the approximated temperature of the smoke layer is examined by comparing the numerical results of the temperature with those obtained through the experiment.
\end{abstract}

KEYWORDS: localized fire, real-scale experiment, smoke layer, soffit, heat flux

\section{INTRODUCTION}

The Building Standards Law of Japan has been revised and introduced a performance-based fire safety design. In the former regulation, fire resistance tests for building components are generally evaluated with the temperature assuming exposure of the component to a fully developed fire. Given a sufficiently wide space in a building or a sufficiently wide opening for the space comparing with the fire load, for example parking buildings, atriums, airport etc. any fire would

*Current address: Consultants' Group of Fire Safety Design, Nihon Bousai INST.LTD, Kyobashi -Kitami bldg, 3-1-9 Hacchobori, Chuo-ku, Tokyo 104-0032, Japan 
be of fuel-controlled type and the effect of heating on structural members could be localized. If a load bearing member is heated only locally in fire, it is believed not only that the heating condition of the member become less significant than in a fully-developed fire but also that conduction loss through the member itself contribute to keep the exposed part cooler. This is due to the thermal conductivity of metal being much higher than that of other construction materials. Therefore in the case where a load bearing member is heated only locally in fire, if a new method is established which can accurately predict the temperature of the components, the fire safety design will become more rational. Previously we evaluated a typical case of a localized fire, in which the Hsection steel beam installed beneath the ceiling and exposed to localized heating with a heat source on the floor, and heating conditions of the member were measured through a small-scale experiment (hereinafter the small-scale test or small-scale experiment means the previous experiments described in Ref. [1]). Subsequently, we have formulated heat flux distribution on every part of the beam as a function of heat release rate and the distance from the fire source to the member. Then we made FEM, FDM and CFD-based numerical calculation models, and the validity of these models was verified by comparing the numerical temperature results with those obtained through the experiment $[2,3,4,5,6]$. From the results of these studies, we demonstrated the practical feasibility of our FEM and FDM-based models to predict the temperature of members, also proposed a correction method of heat flux data, and developed a heat transfer coefficient for the experimental conditions. In our previous experiments, we used small-scale components, and since the edges of the ceiling were open to the air, the smoke layer forming beneath a ceiling was too thin to fully cover the beam. J.Myllymaki and M.Kokkala have shown the effect of localized fire up on an unloaded, unprotected welded steel beam installed below a lightweight concrete ceiling [7]. The size of the steel beam in VTT tests was typical for car park structures in Finland. The beam in their tests was quite high with a relatively thin web. Total heat flux and temperature distribution of this beam were measured for heat release rates 0.56-3.6 MW. J.Myllymaki and M.Kokkala found that for very large fires $(2.06 \mathrm{MW}$ and greater) that the heat fluxes on all faces of the I-beam became similar.

The final purpose of this study was to apply these methods for practical buildings. In this study, the real-scale experiment has been conducted and compared with the small-scale experiments to verify the applicability. Furthermore, heating conditions of steel beam exposed to the smoke layer were measured experimentally making soffits $\mathrm{o}$ the same equipment (referred to here in as the smoke tests). This paper deals with the effects of the smoke layer which influences upon the heating condition of the beam comparing between the smoke-tests and the real-scale tests. As concerns the method of approximation of the smoke layer temperature, FDM-based calculation has been demonstrated using the average temperature for the boundary conditions to predict the thermal response of the beam.

\section{EXPERIMENTAL SETUP}

The experimental equipment were built assuming a part of a general parking building. The experimental layout is shown in Figure 1. A H-section bare steel beam with the following dimensions were used: $6.0 \mathrm{~m}$ long, $400 \mathrm{~mm}$ (web), $200 \mathrm{~mm}$ (flange), $13 \mathrm{~mm}$ (thickness of web), $15 \mathrm{~mm}$ (thickness of flange). The rectangular flat ceiling consists of $25 \mathrm{~mm}$ thick mineral fiber perlite board with dimensions $6.0 \times 6.0 \mathrm{~m}$. The height of the ceiling is $3.4 \mathrm{~m}$. The ceiling is reinforced by a steel frame and is horizontally placed over the beam held by two box-section steel columns with dimensions $450 \times 450 \times 12 \times 12 \mathrm{~mm}$ at the ends. Four pillars (H-section $150 \mathrm{~mm} \times 75 \mathrm{~mm})$ are set up at each corner of the ceiling for support. 

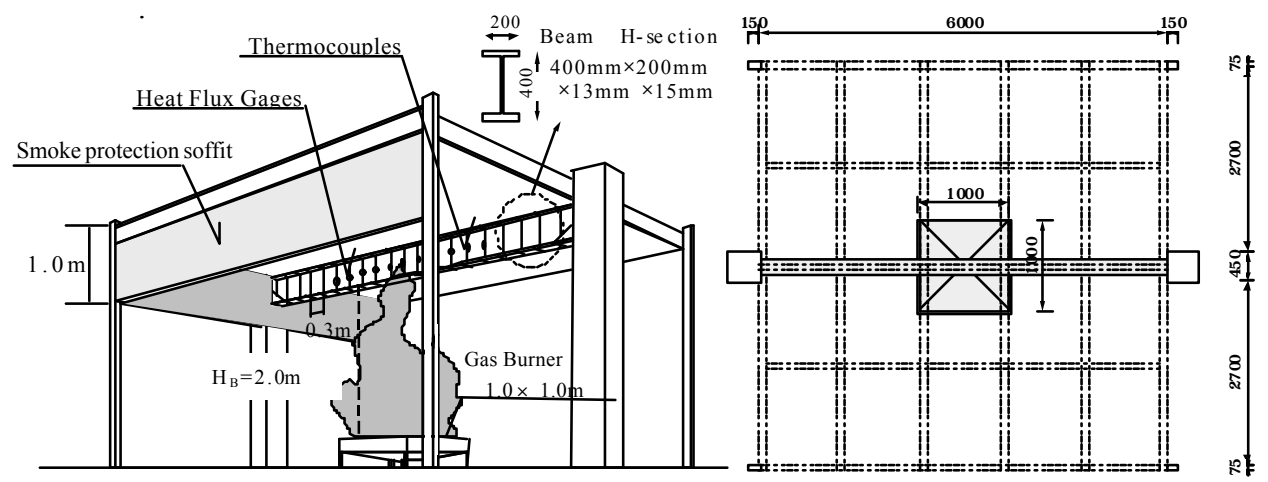

FIGURE 1. Experimental layout of real-scale tests

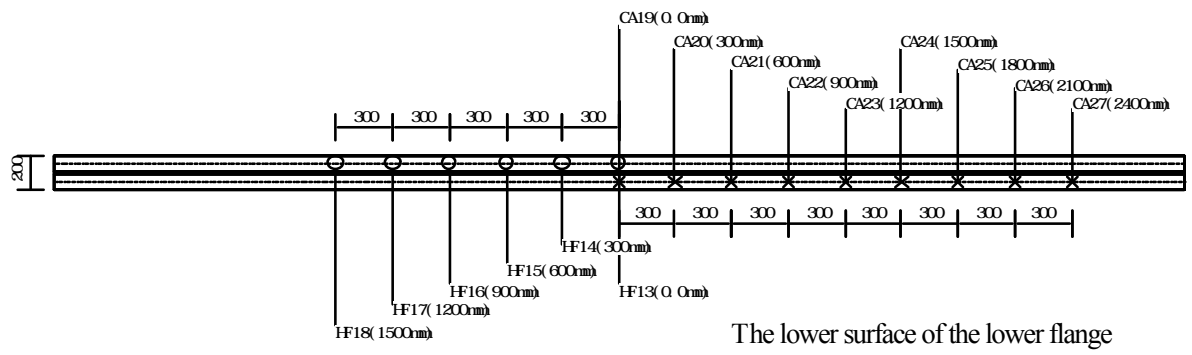

FIGURE 2.Arrangements of heat flux gauges and thermocouples

There are no gaps between the ceiling and the beam. Arrangements of heat flux gauges and thermocouples are shown in Figure 2. Heat flux measurements were made at six horizontal distances from the stagnation point of the beam. Water-cooled Schmidt-Boelter heat flux gages $(\varphi 15 \mathrm{~mm})$ were installed flush with the beam surface through the holes made in the beam. Heat flux to the upper flange, web and also lower surfaces of the lower flange were measured. Since the number of heat flux gages was limited, additional heat flux measurements were obtained by repeating each test condition with the heat flux gages at a different location. This counterplan contributes to avoiding too dense arrangement of the gages which can disturb the flow around the beam. Temperature measurements of the beam were made with thermocouples at the points which were symmetrical to the points of the heat flux gages with regard to the center of the beam. Thermocouples were $0.2 \mathrm{~mm}$ K-type (bare bead with glass braid) and the bead was in contact with the beam surface. At the stagnation point, the thermocouple was slightly separated from the heat flux gage to avoid overlapping. A $1.0 \times 1.0 \mathrm{~m}$ square porous burner was used as the fire source, and was set just under the center of the beam. This burner used propane as the fuel, and was regulated to spout out the flame uniformly. The heat release rate was calculated from the volume of flowing gas and assumed complete combustion. The heat release rates of experimental conditions were controlled with this factor. Since experiments were carried out in the open air, four directions of the equipment were surrounded by wall to avoid the wind. To keep enough ventilation for combustion, we made $1.5 \mathrm{~m}$ spaces between the equipment and the wall. A square $0.3 \times 0.3 \mathrm{~m}$ window was made on the wall to record the flame length by video-camera. In the case of the smoke tests, four smoke protection soffits $(25 \mathrm{~mm}$ thick mineral fiber perlite board with dimensions $1.0 \times 6.0 \mathrm{~m}$ ) are set up at every edge of the ceiling. 


\section{TEST CONDITIONS}

VTT tests in Finland were conducted using a heptane pool and the diameter of the pool D and the amount of heptane in the pool were varied. The test condition of dimension -less height $\mathrm{L} / \mathrm{Hc}$ in VTT tests was varied between 1.43-3.39. The previous Japanese investigation of a flat ceiling above a localized fire source makes it clear that heat flux $q$ at the stagnation point depends on dimension -less height $\mathrm{L}_{\mathrm{f}} \mathrm{Hc}[8,9]$. The correlation between the $\mathrm{L}_{\mathrm{f}} \mathrm{Hc}$ and heat flux to the ceiling at the stagnation point is shown in Figure 3. From this Figure, we can see that there is the increase of heat flux $q$ at the stagnation point between $\mathrm{L}_{\mathrm{H}} \mathrm{Hc}=1.0$ and $\mathrm{L}_{\mathrm{f}} / \mathrm{Hc}=2.5$. We can believe that the importance and advantage of the consideration of localized fire become most significant in this domain. Considering this result, nine combinations of $\mathrm{Q}, \mathrm{D}$ and $\mathrm{H}_{\mathrm{B}}$ were chosen as the experimental conditions of the previous small-scale experiment. The combinations were chosen to divide the whole range of heating condition $1.0<\left(\mathrm{L}_{f} / \mathrm{Hc}\right)<2.5$ into three. At the beginning of the first zone only the flame tips reached to the lower flange surfaces and at the end of the third zone the beam was fully covered by the flame. The height of unconfined flame-tips $\mathrm{L}_{\mathrm{f}}$ is calculated with the estimated heat output using

$$
L_{f}=3.5 Q * n \cdot D
$$

where $\mathrm{n}=2 / 5$ for $\mathrm{Q}^{*} \geqq 1.0$ and $\mathrm{n}=2 / 3$ for $\mathrm{Q}^{*}<1.0[10,11]$.

Table 1 shows specific of the previous small-scale test conditions. The small-scale experiment was not conducted in this paper.

TABLE 1 .Test conditions of previous small-scale test

\begin{tabular}{|c|c|c|c|c|c|}
\hline Burner Size D (m) & Heat Release Rate Q(kW) & Distance $\mathrm{H}_{\mathrm{B}}(\mathrm{m})$ & $Q_{\text {D н }}{ }^{*}(-)$ & $\mathrm{L}_{\mathrm{f}} / \mathrm{H}_{\mathrm{B}}(-)$ & $\mathrm{Q} *(-)$ \\
\hline \multirow{2}{*}{$\begin{array}{c}0.5 \\
\text { (diameter round burner) }\end{array}$} & $\begin{array}{l}100 \\
150 \\
200 \\
\end{array}$ & $\begin{array}{ll}1 & .0 \\
1 & .0 \\
1 & .0 \\
\end{array}$ & $\begin{array}{l}0.179 \\
0.269 \\
0.358 \\
\end{array}$ & $\begin{array}{l}1.111 \\
1.456 \\
1.754 \\
\end{array}$ & $\begin{array}{l}0.51 \\
0.76 \\
1.01 \\
\end{array}$ \\
\hline & $\begin{array}{r}95 \\
130 \\
160 \\
\end{array}$ & $\begin{array}{l}0.6 \\
0.6 \\
0.6 \\
\end{array}$ & $\begin{array}{l}0.366 \\
0.501 \\
0.617 \\
\end{array}$ & $\begin{array}{l}1.790 \\
2.201 \\
2.535 \\
\end{array}$ & $\begin{array}{l}0.48 \\
0.66 \\
0.81 \\
\end{array}$ \\
\hline $\begin{array}{c}1.0 \\
\text { (square burner) }\end{array}$ & $\begin{array}{l}540 \\
750 \\
900\end{array}$ & $\begin{array}{l}1.2 \\
1.2 \\
1.2\end{array}$ & $\begin{array}{l}0.368 \\
0.511 \\
0.613\end{array}$ & $\begin{array}{l}2.155 \\
2.682 \\
3.029\end{array}$ & $\begin{array}{l}0.48 \\
0.67 \\
0.81\end{array}$ \\
\hline
\end{tabular}

From these conditions of small-scale tests, three test conditions $Q=100,150,200 \mathrm{~kW}$ have been chosen to compare with the real-scale experiment. The value of heat release rate $\mathrm{Q}$ of the real-scale experiment was decided using the dimensionless heat release rate $\mathrm{Q}_{\mathrm{DHB}}{ }^{*}$, with $\mathrm{H}_{\mathrm{B}}$ as a characteristic length-scale.

$$
Q_{D H B}{ }^{*} \equiv Q / \rho C_{P} T_{0} g^{1 / 2} D H_{B}{ }^{3 / 2}
$$

The heat release rate $\mathrm{Q}$ of the real-scale experiment has been calculated in such condition that the value $\mathrm{Q}_{\mathrm{DHB}}{ }^{*}$ of real-scale experiments is equal to that of the small-scale experiments. The specific real-scale tests conditions are shown in Table 2.

\begin{tabular}{|c|c|c|c|c|c|}
\hline Burner Size D (m) & Heat Release Rate Q(kW) & Distance Нв $(\mathrm{m})$ & Qрнв* (-) & $\mathrm{Lf} / \mathrm{Hв}(-)$ & $Q^{*}(-)$ \\
\hline $\begin{array}{c}1.0 \\
\text { (square burner) }\end{array}$ & $\begin{array}{r}569 \\
848 \\
1127\end{array}$ & $\begin{array}{l}2.0 \\
2.0 \\
2.0\end{array}$ & $\begin{array}{l}0.179 \\
0.269 \\
0.358\end{array}$ & $\begin{array}{l}1.1 \\
1.5 \\
1.8\end{array}$ & $\begin{array}{l}0.51 \\
0.76 \\
1.01\end{array}$ \\
\hline
\end{tabular}

TABLE 2 .Test conditions of real-scale tests 
TABLE 3 .The peak heat fluxes

of the real scale test $(\mathrm{kW})$

\begin{tabular}{|l|r|r|r|}
\hline HRR & \multicolumn{1}{|c|}{$569 \mathrm{~kW}$} & \multicolumn{1}{|c|}{$848 \mathrm{~kW}$} & \multicolumn{1}{|c|}{$1127 \mathrm{~kW}$} \\
\hline \hline lower flange & 21.115 & 42.318 & 58.963 \\
\hline web & 15.610 & 25.744 & 50.604 \\
\hline upper flange & 7.390 & 18.163 & 37.207 \\
\hline
\end{tabular}

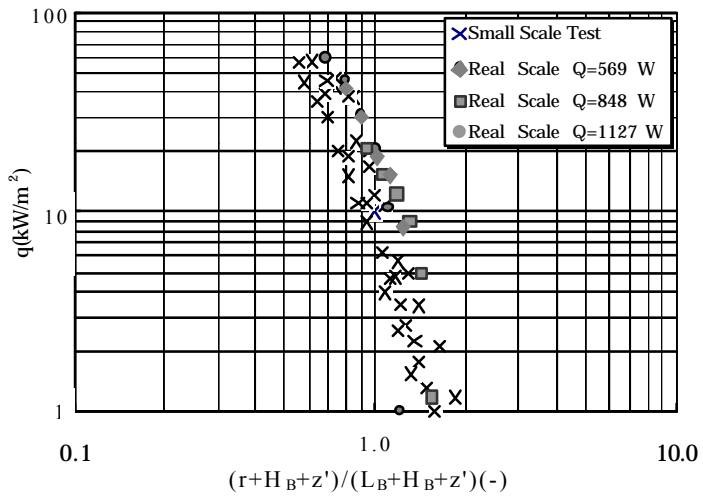

FIGURE 4. Heat flux to the lower surface of lower flange

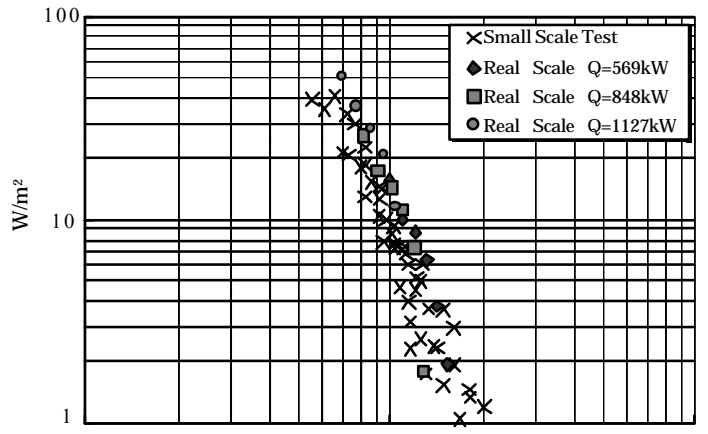

0.1

1.0

10.0

$\left(r+H c+z^{\prime}\right) /\left(\mathrm{Lc}+\mathrm{Hc}+\mathrm{z}^{\prime}\right)(-)$

FIGUR E 5. Heat flux to the web

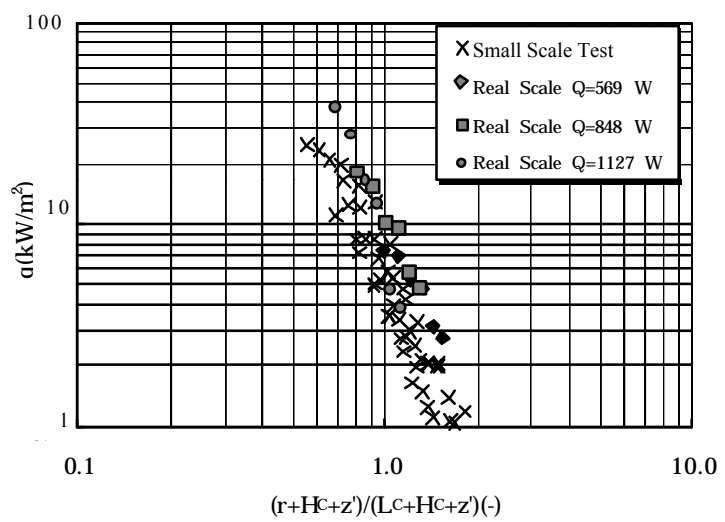

FIGURE 6. Heat flux to the lower surface of upper flange
These three combinations of D,Q and $\mathrm{H}_{\mathrm{B}}$ have been chosen not only for the real-scale test conditions but also for the smoke tests.

\section{RESULTS \\ Comparison between the real -scale and the small-scale experiments}

From the results of the small-scale experiments, it has become clear that heat flux to the lower surface of the lower flange is controlled primarily by the flame length flowing along the lower surface of the beam $\left(\mathrm{L}_{\mathrm{B}}\right.$ as the length) and the other part of the beam is controlled by the flame length flowing under the ceiling $\left(\mathrm{L}_{\mathrm{C}}\right)$. As for the small-scale experiments, the heat flux distribution on every part of the beam has been represented as a function of the radial distance from the stagnation point (r) which is normalized by the flame tip length $\left(\mathrm{L}_{\mathrm{B}}\right.$ or $\left.\mathrm{L}_{\mathrm{C}}\right)$, virtual source depth $\left(\mathrm{z}^{\prime}\right)$ and the height $\left(\mathrm{H}_{\mathrm{B}}\right.$ or $\left.\mathrm{H}_{\mathrm{C}}\right)$. In this paper, the flame length $\left(\mathrm{L}_{\mathrm{B}}, \mathrm{L}_{\mathrm{C}}\right)$ is calculated using the following equations [5].

$$
\begin{aligned}
& L_{B}=H_{B}\left(1.82 Q{ }^{*{ }_{D H B}{ }^{03}}-1\right) \\
& L_{C}=H c\left(2.04 Q{ }^{*}{ }_{D H c}{ }^{0.33}-1\right)
\end{aligned}
$$

with dimensionless heat release rates

$$
\begin{aligned}
& Q *_{D H_{B}} \equiv Q / \rho C_{P} T_{0} g^{1 / 2} D H_{B}{ }^{3 / 2} \\
& Q{ }^{*}{ }_{D H C} \equiv Q / \rho C_{P} T_{0} g^{1 / 2} D H_{C}{ }^{3 / 2}
\end{aligned}
$$

And virtual source depth (z') [11] is expressed by

$$
\begin{aligned}
& z^{\prime}=2.4 D\left(Q^{* 2 / 5}-Q^{* 2 / 3}\right) \quad\left(Q^{*}<1\right) \\
& z^{\prime}=2.4 D\left(1-Q^{* 2 / 5}\right) \quad\left(Q^{*} \geqq 1\right)
\end{aligned}
$$

The range of $\left(\mathrm{r}+\mathrm{H}_{\mathrm{B}}+\mathrm{Z}^{\prime}\right) /\left(\mathrm{L}_{\mathrm{B}}+\mathrm{H}_{\mathrm{B}}+\mathrm{z}^{\prime}\right)<$ $1, \quad\left(\mathrm{r}+\mathrm{H}_{\mathrm{C}}+\mathrm{z}^{\prime}\right) /\left(\mathrm{L}_{\mathrm{C}}+\mathrm{H}_{\mathrm{C}}+\mathrm{z}^{\prime}\right)<1$ is the parts where flame exist. Myllymaki and Kokkala measured peak heat fluxes were reached at the range of $\left(\mathrm{r}+\mathrm{H}+\mathrm{z}^{\prime}\right) /\left(\mathrm{L}+\mathrm{H}+\mathrm{z}^{\prime}\right) \sim 0.5$ in 
VTT test mentioned above [7]. The measured peak heat fluxes of the real scale test in Japan are shown in Table 3. The peak heat fluxes of the real scale test are reached at $\left(\mathrm{r}+\mathrm{H}+\mathrm{z}^{\prime}\right) /\left(\mathrm{L}+\mathrm{H}+\mathrm{z}^{\prime}\right) \sim 0.7$. It has been shown (Myllymaki and Kokkala 2000), that the heat flux to the downward surface of the lower flange was about $30 \%$ higher than the heat flux to web and upper flange in the case of smaller flames $(565<\mathrm{Q}$ $\left.<970 \mathrm{~kW}, 1.43<\left(\mathrm{L}_{\mathrm{f}} / \mathrm{Hc}\right)<1.85\right)$. With larger flames $\left(2060<\mathrm{Q}<3870 \mathrm{~kW}, 2.58<\left(\mathrm{L}_{\mathrm{f}} \mathrm{Hc}\right)<3.39\right)$ the heat flux to web and upper flange was higher than the heat flux to the lower flange. Figures 4 - 6 make a comparison between the real-scale test and the small-scale test of the heat flux to every part of the beam. The heat flux to the downward surface of the lower flange is always higher than the heat flux to web and upper flange under the same experimental conditions of real-scale test $(569<\mathrm{Q}<1127$ $\left.\mathrm{kW}, 0.51<\left(\mathrm{L}_{\mathrm{f}} / \mathrm{Hc}\right)<1.01\right)$. Figures $4-6$ indicate that the data obtained through the real-scale experiment are highly concentrated along one single line and are distributed similar to the data of the small-scale experiment. The heat flux to the lower surface of the lower flange obtained through the real-scale experiments distributed near from the maximum values of the small-scale experiments as shown in Figure 4. In the domain near the stagnation point, both the heat flux data of the web and the upper flange obtained from the real-scale tests are higher than that of the small-scale experiments as shown in Figure 5 and Figure 6. The maximum difference of the heat flux to the upper flange is $17 \mathrm{~kW} / \mathrm{m}^{2}$ at the stagnation point.

\section{THE EFFECTS OF THE SMOKE LAYER}

\section{Temperature measurements of smoke layer}

In both the small and the real-scale experiments, the smoke layer forming beneath a ceiling would be too thin to fully cover the beam. In most cases of practical buildings, walls or smoke protection soffits may be built under the ceiling and it will interrupt the smoke movement. Four smoke protection soffits (height $1.0 \mathrm{~m}$ ) were set up along every edge of the ceiling to

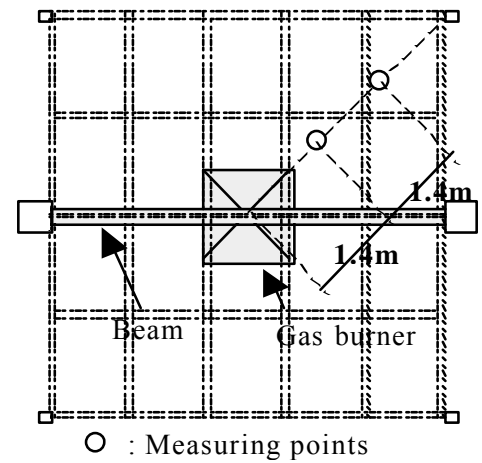

FIGURE7.Temperature measurements of the smoke layer

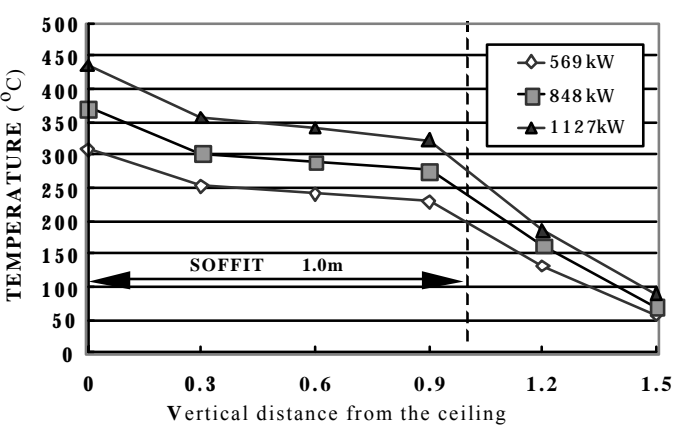

FIGURE 8. The vertical temperature distribution at $1.4 \mathrm{~m}$ from the center

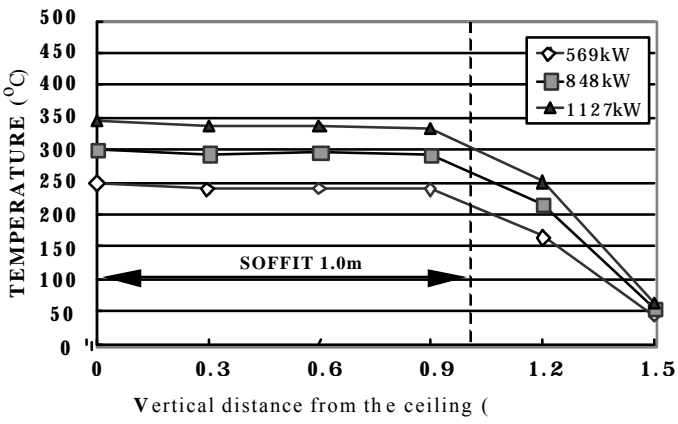

FIGURE 9. The vertical temperature distribution at $2.8 \mathrm{~m}$ from the center 


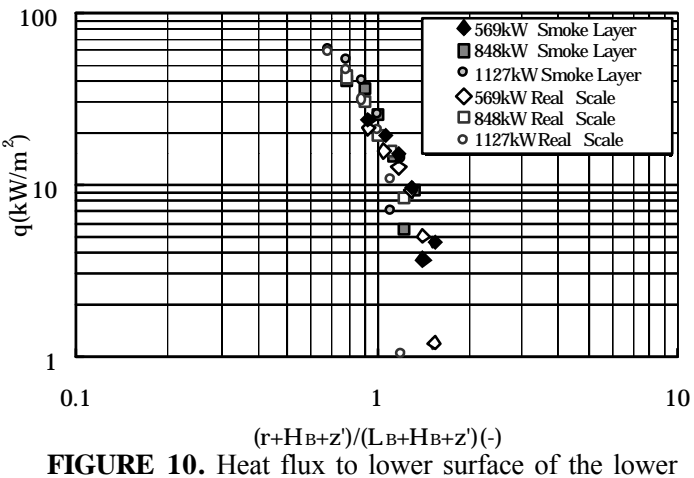

FIGURE 10. Heat flux to lower surface of the lower flange

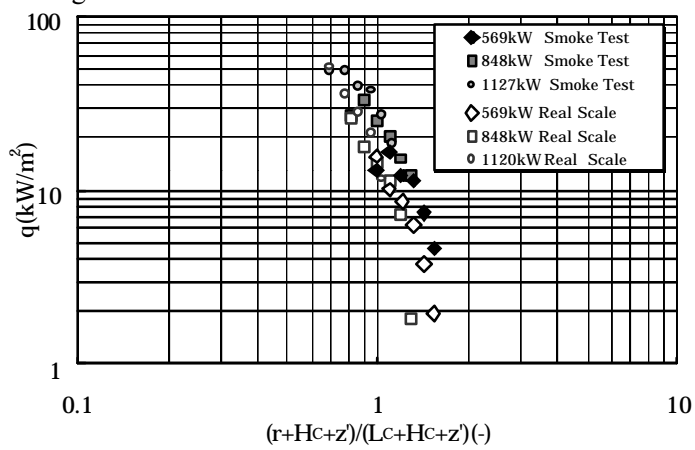

FIGURE 11. Heat flux to the web

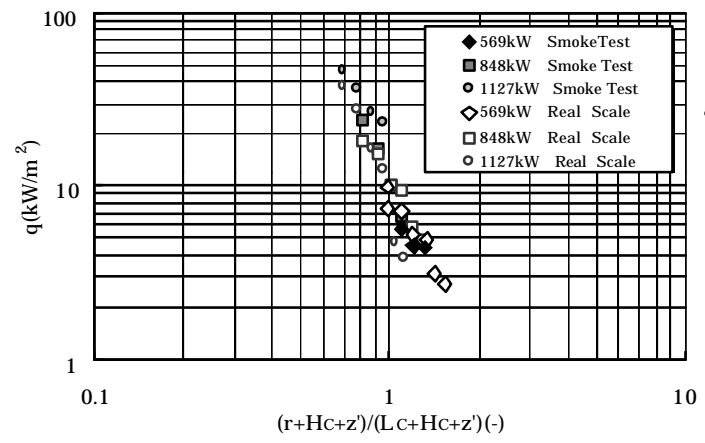

FIGURE 12. Heat flux to lower surface of the upper flange

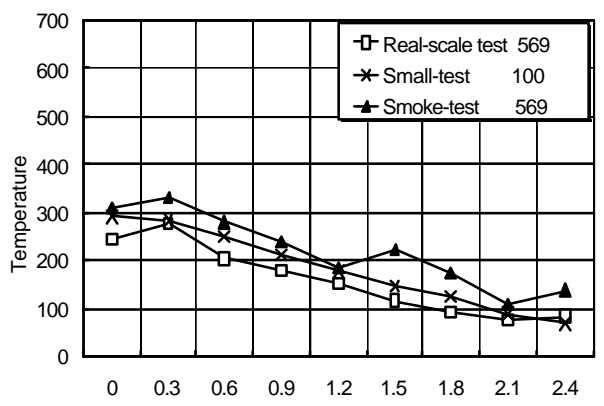

Distance from the stagnation point $\mathrm{r}(\mathrm{m})$

$\mathrm{Q}_{\mathrm{DHB}}{ }^{*}=0.269$

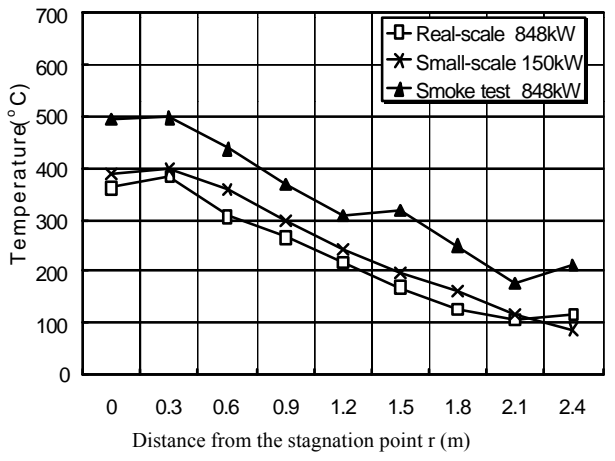

$\mathrm{Q}_{\text {D H B }}{ }^{*}=0.358$

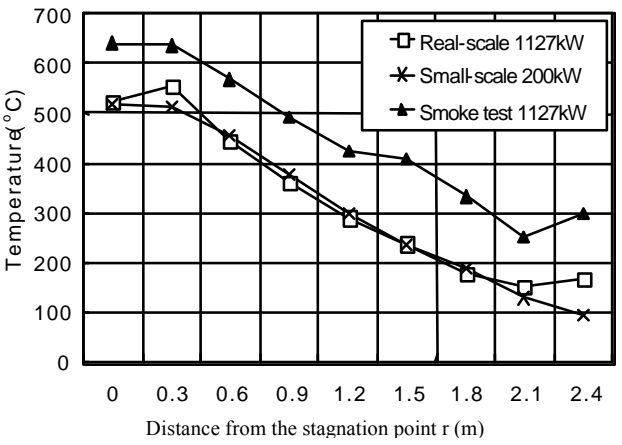

FIGURE 13. Temperature distributions along the beam

develop a deeper smoke layer. The vertical temperature distributions of the smoke layer were measured every $30 \mathrm{~cm}$ distance from the ceiling surface at two points as shown in Figure 7.

The vertical temperature distributions at $1.4 \mathrm{~m}$ and $2.8 \mathrm{~m}$ from the center are shown in Figure 8 and 9 respectively. From these figures, the temperatures of the smoke layer decrease with vertical distance from the ceiling surface at the both points. Although the difference between the temperature of $0 \mathrm{~m}$ and $0.3 \mathrm{~m}$ from the ceiling surface is about $100-150^{\circ} \mathrm{C}$ under the same experimental conditions at the point $1.4 \mathrm{~m}$ from the center, these differences become insignificant at the point $2.8 \mathrm{~m}$ from the center. 


\section{Comparison between the smoke tests and the real-scale tests}

Results of heat flux measurements of smoke tests and the real-scale tests are summarized against the radial distance from the stagnation point, $r$, normalized by $\mathrm{L}_{\mathrm{B}}$ or $\mathrm{L}_{\mathrm{C}}, \mathrm{z}^{\prime}$ and $\mathrm{H}_{\mathrm{B}}$ or $\mathrm{H}_{\mathrm{C}}$ in Figures $10-12$. In these Figures, the lowest $\left(\mathrm{r}+\mathrm{H}_{\mathrm{B}}+\mathrm{z}^{\prime}\right) /\left(\mathrm{L}_{\mathrm{B}}+\mathrm{H}_{\mathrm{B}}+\mathrm{z}^{\prime}\right)$ and $\left(\mathrm{r}+\mathrm{H}_{\mathrm{C}}+\mathrm{Z}^{\prime}\right)$ $/\left(\mathrm{L}_{\mathrm{C}}+\mathrm{H}_{\mathrm{C}}+\mathrm{Z}^{\prime}\right)$ value are shown the heat flux levels at the stagnation point. As concerns the lower surface of the lower flange, there is not much difference between heat flux distributions with and without a smoke layer in these experiments. At the stagnation point, with same heat release rate $\mathrm{Q}$, the heat flux to the web measured in the smoke tests were in good agreement with that of the real-scale tests. The heat fluxes to the lower surface of the upper flange measured in the smoke tests were larger than that of the real-scale tests. Heat flux to the web in particular, the difference of heat flux is approximately $8-15 \mathrm{~kW} / \mathrm{m}^{2}$ between the smoke test and the real-scale test except the stagnation point. We can also see that the heat flux data of the lower flange is more scattered in the range of $\left(\mathrm{r}+\mathrm{H}_{\mathrm{B}}+\mathrm{Z}^{\prime}\right) /\left(\mathrm{L}_{\mathrm{B}}+\mathrm{H}_{\mathrm{B}}+\mathrm{Z}^{\prime}\right)>1$ (where no flame exist) than in the range of $\left(\mathrm{r}+\mathrm{H}_{\mathrm{B}}+\mathrm{z}^{\prime}\right)$ $/\left(\mathrm{L}_{\mathrm{B}}+\mathrm{H}_{\mathrm{B}}+\mathrm{Z}^{\prime}\right)<1$. On the whole, the heat flux data of web is scattered significantly in all domains, both heat flux data measured at the smoke test and the real-scale test were found to be highly concentrated along two lines.

Both these results suggest that, except for the stagnation point, the heat flux to the web received was influenced from the smoke layer than other parts of the beam.

\section{Temperature distributions}

Concerning the same experimental condition of $\mathrm{QDHB}_{\mathrm{DH}}{ }^{*}$, the temperature distributions of lower flange measured on the small-scale, the real-scale and the smoke tests are shown in Figure 13. All three figures show that the temperature distributions decrease along the axial direction of the beam. These experimental values are under the conditions in which the member reached almost steady state in temperature. As for these three experimental conditions, the temperature distributions of the real-scale test almost agree with that of small-scale tests respectively. By comparing the data of the smoke tests with the real-scale tests, we determined the following: under the same experimental conditions, the difference of the temperature is almost uniform at the same distance from the stagnation point except the domain of $1.2-2.1 \mathrm{~m}$ from the stagnation point . The reason of this difference is not known. But we have to note that there 
were joints of beam in this area. The difference of the temperature between the real-scale and the smoke test is about $60-130^{\circ} \mathrm{C}$ at the stagnation point.

\section{Approximation of the smoke layer}

A temperature analysis model based upon FDM is shown in Figure 14. A rectangular prism model for analysis was constructed neglecting the sectional shape of the beam, which has the same surface area and the same volume as those of the H-shaped beam. Using this calculation model, we considered heat transfer in a linear temperature field along the beam's axial direction, transient temperature calculation was carried out for half of the beam. This calculation model is divided into 11 elements in the axial direction only. From the results of the small-scale experiment, heat flux distribution on every part of the beam was formulated as a function of flame length and distance from the fire source to the member, within error of \pm $20 \%$. The small-scale experimental data of heat flux, regressed in ten approximation equations by using the discrimination equation, is substituted for the boundary conditions of the real-scale and smoke tests calculation. Details of the FDM calculation model and discrimination equations are described in Ref.[3]. The net heat transfer to the specimen surface depends upon the surface temperature of the specimen itself. However, the heat flux gages used were of water cooling type, so there was a considerable difference between the specimen surface temperature $\boldsymbol{\theta} s$ and that of the measurement surface of heat flux gage $\theta g$.

If the data of the measurement surface of the heat flux gage is used as it is, some error may occur due to the temperature difference mentioned above. Modeling of a heat balance on the specimen surface as shown Figure 15 makes it possible to express the net heat flux to the specimen surface $q_{\text {net }}$ by the following equation;

$q_{n e t} \equiv q_{\exp }-h(\theta s-\theta a)-\sigma \varepsilon_{s}\left(\theta s^{4}-\theta a^{4}\right)+\sigma \varepsilon_{g}\left(\theta g{ }^{4}-\theta a^{4}\right)$

Here, the value of $q_{\exp }$ is given by the approximation equations mentioned above. Assuming that the difference of the temperature between heat flux gage and ambient air can be neglected, $q_{n e t}$ is used in the boundary condition of the calculation. As concerns the convection heat transfer coefficient $\mathrm{h}$, we implemented comparisons between temperature analysis and experiment; after repeating tries and errors, we determined a heat transfer coefficient of $\mathrm{h}=0.01 \mathrm{~kW} / \mathrm{m}^{2} \mathrm{~K}$ which may ensure a good conformity between calculation and experiment. This value is used for the FDM calculation. Under the same experimental condition of Q, a comparison between calculated and measured values of the temperature of real-scale experiments are shown in Figure 16. In this calculation, the value of $30^{\circ} \mathrm{C}$ is substituted as the ambient air temperature $\theta$ a. Similarly, Figure 17 shows the calculation results and measured values of the smoke-tests. In this case, the smoke layer temperatures shown in Figure 9 and 10 were used to calculate the average temperatures, and these are substituted as the ambient air temperature $\theta$ a .The average temperatures of the smoke layer are shown in Table 4.

TABLE 4. The average temperature of the smoke layer $\left({ }^{\circ} \mathrm{C}\right)$

\begin{tabular}{|l|c|c|c|}
\hline & $569 \mathrm{~kW}$ & $848 \mathrm{~kW}$ & $1127 \mathrm{~kW}$ \\
\hline AVERAGE & 231.3 & 285.5 & 327.0 \\
\hline
\end{tabular}

From the Figure 16 and 17, we know that, in the experimental condition $\mathrm{Q}=569 \mathrm{~kW}$ of both the real-scale and the smoke tests, the calculation values of the temperature almost agree with that of the lower flange and web measured at the experiments. In the case of $\mathrm{Q}=848$ and $1127 \mathrm{~kW}$, the calculation values of the temperature are between the upper and lower flange temperatures measured in both the real-scale and the smoke tests. As for experimental data of lower 
flange and web, the temperature $0.3 \mathrm{~m}$ from stagnation point is always higher or near to the value of stagnation point. At the point $0.3 \mathrm{~m}$ from the stagnation point, the difference between calculation and experiment value of both the real-scale and the smoke tests reach a maximum. In the case of the real-scale tests with $\mathrm{Q}=1127 \mathrm{~kW}$, the maximum value of the difference is about $25 \%$ of experimental value. If we assumed the average temperatures of the smoke layer was the ambient air temperature $\theta$ a, it is possible to calculate the temperature distribution of the beam within error $20 \%$ of experimental value.
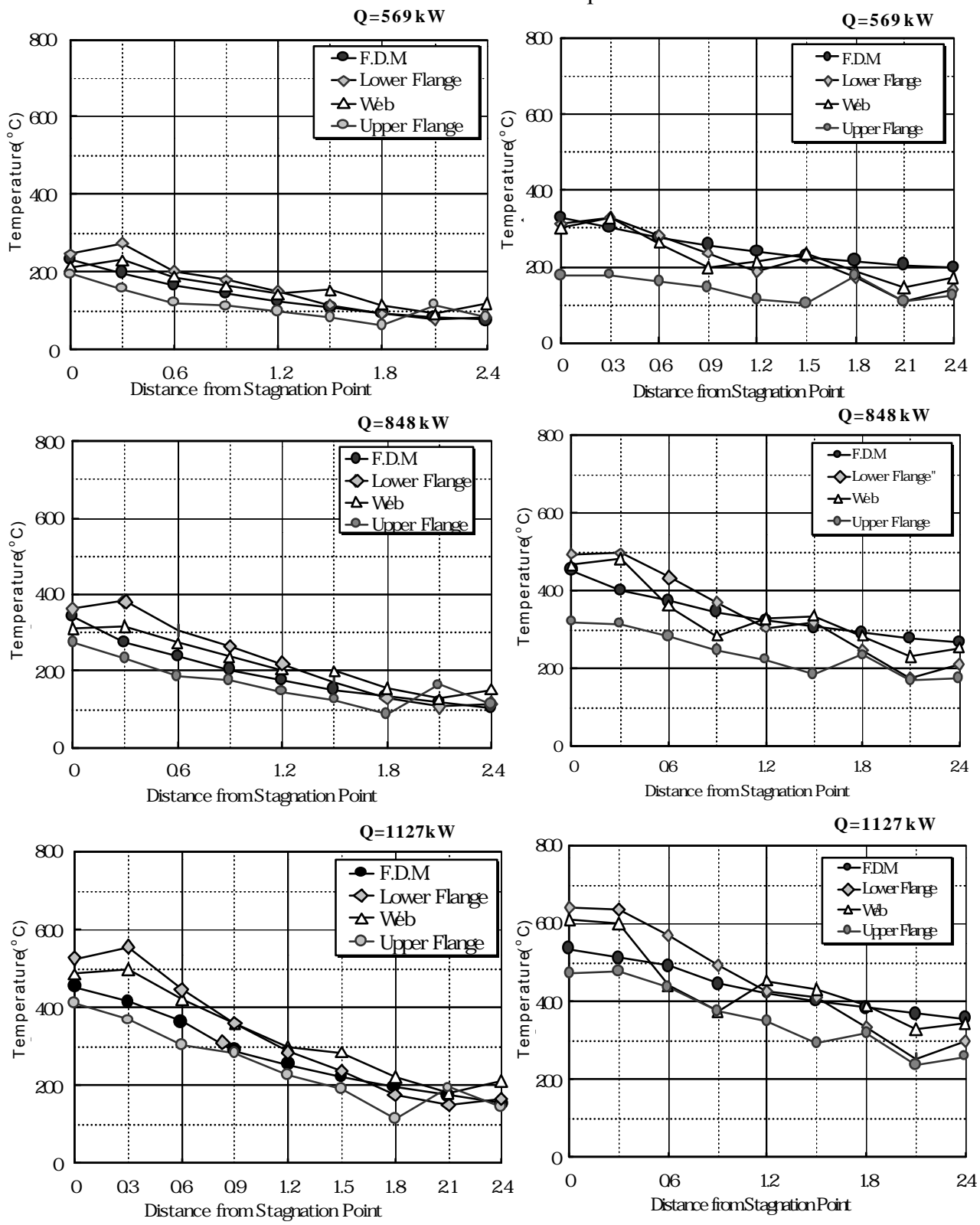

FIGURE 16.F.D.M. calculation results and measured values of real-scale test

FIGURE 17.F.D.M. calculation results and measured values of smoke test 


\section{CONCLUSIONS}

Heating conditions of the steal beam exposed to a localized fire source have been measured through real-scale and the smoke experiments. The data of the real-scale experiment have been compared with the previous small-scale experiments at different cross-sectional locations. FDM-based numerical calculation has been

demonstrated to predict the thermal response of the beam using the average temperature. From the results of the experiments, the following conclusions can be drawn.

(1) Heat flux to the lower surface of the lower flange obtained through the real-scale experiments correspond to the maximum values of the small-scale experiments. In the domain near the stagnation point, both heat flux data of the web and the upper flange obtained through the real-scale tests are higher than that of the small-scale tests. The maximum difference of the heat flux to the upper flange is $17 \mathrm{~kW} / \mathrm{m}^{2}$ at the stagnation point.

(2) The heat flux to the lower surface of the lower flange measured in the smoke tests agree well with that of the real-scale tests. For the web and upper flange, heat flux distributions during the smoke tests are larger than that of the real-scale tests. The heat flux to the web is approximately $8-15 \mathrm{~kW} / \mathrm{m}^{2}$ higher in the smoke tests compared with data from the real-scale tests.

(3) The temperature distributions of the real-scale tests almost agree with that of small-scale tests. Under the same experimental conditions, the difference in the temperature between the smoke tests and the real-scale tests is nearly uniform at the same distance from the stagnation point. In the experimental conditions of $\mathrm{Q}_{\mathrm{DHB}}{ }^{*}=0.269$, the maximum difference of temperature between the smoke tests and the real-scale tests is about $130^{\circ} \mathrm{C}$ at the stagnation point.

(4) If we substituted the average temperatures of the smoke layer to the FDM calculation, it is possible to calculate the temperature distribution of the beam within error of $20 \%$.

\section{ACKNOWLEDGMENTS}

The authors wish to thank Prof. M.Kokkala for his helpful suggestions to carry the study. The authors would like to thank Dr.A. Pchelintsev, VTT Building Technology for the advice of numerical simulation model. The authors are also indebted to Messrs. Yusuke Tamura, Kenji Koshikawa, Miss. Sawori Namekawa, and Miss Akiko Nanbu, students of the Department of Architecture and Architectural Engineering, School of Science and Engineering Science University of Tokyo, Messrs. DonGun Nam, and Shigeto Ito, students of the Department of Architecture School of Science and Engineering Waseda University for the assistance in the present experiments .

\section{TERMINOLOGY}

$\mathrm{D}$ : characteristic fuel size $(\mathrm{m})($ diameter for a round fuel and the length of one side for a square fuel)

$\mathrm{H}_{\mathrm{B}}$ : height between the burner surface and the bottom of the beam $(\mathrm{m})$

$\mathrm{H}_{\mathrm{C}}$ : height from fire source to the ceiling $(\mathrm{m})$

q: heat flux at the stagnation point $\left(\mathrm{kW} / \mathrm{m}^{2}\right)$

$q_{\text {net }}$ :net heat flux to the specimen surface $\left(\mathrm{kW} / \mathrm{m}^{2}\right)$

$q_{\text {exp }}$ : heat flux given by the approximation equations $\left(\mathrm{kW} / \mathrm{m}^{2}\right)$

$L_{B}$ : the length of the flame flowing along the lower surface of the beam (m)

$\mathrm{L}_{\mathrm{C}}$ : the length of the flame flowing under the ceiling $(\mathrm{m})$

$\mathrm{L}_{\mathrm{f}}$ : the height of unconfined flame-tips (m)

Q: heat release rate $(\mathrm{kW})$

$\mathrm{Q}^{*}$ d dimensionless heat release rate $\left(\mathrm{Q} / \mathrm{p} \mathrm{C}_{\mathrm{p}} \mathrm{T}_{0} \mathrm{~g}^{1 / 2} \mathrm{D}^{5 / 2}\right)(-)$ 
$\mathrm{Q}_{\mathrm{DHB}}{ }^{*}$ : dimensionless heat release rate $\left(\mathrm{Q} / \mathrm{\rho} \mathrm{C}_{\mathrm{p}} \mathrm{T}_{0} \mathrm{~g}^{1 / 2} \mathrm{DH}_{\mathrm{B}}{ }^{3 / 2}\right)(-)$

$\mathrm{Q}_{\mathrm{DHC}}{ }^{*}$ : dimensionless heat release rate $\left(\mathrm{Q} / \mathrm{p} \mathrm{C}_{\mathrm{p}} \mathrm{T}_{0} \mathrm{~g}^{1 / 2} \mathrm{DH}_{\mathrm{C}}{ }^{3 / 2}\right)(-)$

g: gravitational acceleration $\left(\mathrm{ms}^{-2}\right)$

$\mathrm{h}$ : convection heat transfer coefficient $\left(\mathrm{kW} / \mathrm{m}^{2} \mathrm{~K}\right)$

z': location of virtual source $(\mathrm{m})$

$\epsilon$ :emissivity (-)

$\epsilon \mathrm{g}$ :emissivity of heat flux gage (-)

$\epsilon \mathrm{s}$ :emissivity of beam surface (-)

$\theta$ a :temperature of ambient air $(\mathrm{K})$

$\theta \mathrm{g}$ :temperature of heat flux gage $(\mathrm{K})$

$\theta \mathrm{s}:$ temperature of the beam $(\mathrm{K})$

$\rho:$ density of ambient air $\left(\mathrm{kgm}^{-3}\right)$

$\sigma:$ Stefan-Boltzman Constant $\left(\mathrm{Wm}^{-2} \mathrm{~K}^{-4}\right)$

\section{REFERENCES}

1) Wakamatsu,T.,Hasemi,Y.,Yokobayashi,Y.and A .V. Pchelintsev, 1996 "Experimental Study on the Heating Mechanism of a Steel Beam Exposed to a Localized Fire", Proceedings, Interflam '96 Cambridge pp509-518

2) Wakamatsu,T.,Hasemi,Y., Yokobayashi,Y.and A.V.Pchelintsev,"Heating Mechanism of Building Components Exposed to a Localized Fire - FEM Thermal and Structural Analysis of a Steel Beam Under Ceiling," Proceedings, OMAE '97 Yokohama 1997.

3) Wakamatsu,T.,Hasemi, Y., "Heating Mechanism of Building Components Exposed to a Localized Fire- FDM Thermal Analysis of a Steel Beam Under Ceiling -," Fire Science and Technology - Proceedings of the Third Asia-Oceania Symposium, Singapore pp335-346,1998.06

4) A.V.Pchelintsev, Hasemi,Y., Maria Nikolaenko, Alexander Skibin, Wakamatsu,T., 1996 "Three Dimensional Thermal Analysis of Steel Beams Exposed to a Localized Fire", Proceedings, Interflam '96 Cambridge pp519-529

5) A.V.Pchelintsev, Hasemi,Y., Wakamatsu,T., Yokobayashi,Y., "Experimental and Numerical Study on the Behavior of a Steel Beam under Ceiling Exposed to a Localized Fire" Proceedings of the fifth international symposium of IAFSS pp1153-1164 Melbourne 1997.

6) Wakamatsu,T.,Hasemi,Y.,A .V. Pchelintsev, Hayashi,Y.,"CFD Prediction of Heat Transfer to a Steel Beam under Ceiling' Fire Science and Technology - Proceedings of the Fourth Asia-Oceania Symposium, pp553-564 Japan 2000.

7) Myllymaki,J., Kokkala,M. :Thermal Exposure to a High Welded HBeam above a Pool Fire, First International Workshop on Structures in fire ,Copenhagen, June 2000.

8) Kokkala,M. : Experimental Study of Heat Transfer to Ceiling from an Impinging Diffusion Flame, Proc. Third International Symposium on Fire Safety Science, Edinburgh, 1991.

9) Hasemi,Y.,Yokobayashi,S.,Wakamatsu,T.,Pchelintsev,A.,: Firesafety of Building Components Exposed to a Localized Fire - Scope and Experiments on Ceiling/Beam System Exposed to a Localized Fire, ASIAFLAM'95Hong Kong 1995

10) Cetegen,B., Zukoski,E.E., Kubota,T.: Entrainment and Flame Geometry of Fire Plumes, NBS-GCR-82-402, 1982.

11) Hasemi,Y., and Tokunaga,t.,Flame Geometry Effects on the Buoyant Plumes from Turbulent Diffusion Flames,Fire Science and Technology,Vol.4,No.1,1984. 